\title{
An efficient protocol for somatic embryogenesis of garlic (Allium sativum L.) using root tip as explant
}

\author{
M. N. Hassan ${ }^{1 *}$, M. S. Haque ${ }^{2}$, M. M. Hassan ${ }^{3}$ and M. S. Haque ${ }^{4}$ \\ ${ }^{1}$ Department of Environmental Sanitation, ${ }^{2}$ Department of Genetics and Plant Breeding, ${ }^{4}$ Department of Post-harvest \\ Technology and Marketing, Patuakhali Science and Technology University, Dumki, Patuakhali-8602 and ${ }^{3}$ Deartment \\ of Biotechnology, Bangladesh Agricultural University, Mymensingh-2202, Bangladesh, ${ }^{*} E-m a i l: ~ n a z m u l-j h @$ \\ yahoo.com
}

\begin{abstract}
Genetic improvement of garlic through conventional breeding is very difficult due to sterile nature of its flower. Hence, an alternative system is desirable to induce genetic variation. Tissue culture could be a good opportunities and somatic embryogenesis is one of the potential techniques of tissue culture for in vitro regeneration of garlic plant. The successes and production of somatic embryo depends on several factors such as optimization of media components, genotypes and explant type. Therefore, in the present investigation, garlic root tips were used as explant for callus and somatic embryo induction under different plant growth regulator combination. It was found that $\mathrm{MS}^{2} 1.0 \mathrm{mg} \mathrm{\textrm {I } ^ { - 1 }}$ 2,4-D was the most favorable ( $86.10 \%$ regeneration with $2.19 \mathrm{~cm}$ callus diameter) for callus induction. This concentration also induced and produced good quality somatic embryo. In addition, MS+2.0 mg I' ${ }^{-1}$ Kinetin gave better regeneration of somatic embryo and yielded the highest number (4.670) and longest length $(7.0 \mathrm{~cm})$ of shoots per callus. The procedure used a single hormonal signal for callus and somatic embryo induction as well as hormone free medium for further development of plantlet. Besides, maximum duration for callus induction and somatic embryo production was 17 and 10.67 days respectively. Thus, it appears that the protocol is cheap and time bound and particularly useful for conducting experiment for genetic improvement of garlic. Furthermore, as the protocol is cost effective, it can be further tested for commercial feasibility.
\end{abstract}

Keywords: Root tip, Explant, In vitro culture, Somatic embryogenesis, Plantlet regeneration

\section{Introduction}

Garlic does not produce fertile seeds and vegetative propagation is the usual way for its reproduction. But, vegetative propagation offer limited chances for creating genetic variation and gives low multiplication rate in the field. In vitro plant production of garlic through tissue culture could overcome these difficulties and provide excellent opportunities for its genetic improvement by the process of genetic engineering and molecular gene transfer. Thereby, it could facilitate the rapid development of new varieties which yield high and are resistant to different stresses like viral and fungal diseases.

One of the prospective and potential ways of in vitro plant culture of garlic is the somatic embryogenesis. But, the optimization of media constituents is critical for ensuring better yield and quality of somatic embryo production (Lee et al., 2009). Besides, in vitro regeneration of plant depends on several factors such as the explant type and its physiological condition, genotype and growth regulator combination used in the culture medium.

Earlier several studies (Zdravkovic'-Korac'et al., 2010; Nasim et al., 2010; Luciani et al., 2006; Fereol et al., 2005; Khan et al., 2004; Haque et al., 2003; Fereol et al., 2002; Roksana et al., 2002; Robledo et al., 2000) were devoted to optimize the media components and selection of explant for the development of a suitable protocol for efficient plantlet regeneration in garlic. These studies used different types of explants (shoot, leaf, root, inflorescence etc.) for plant regeneration. Among these explants type, root explants are easy to excise, labor intensive, cost effective and available at a higher rate compared to a single shoot tip or basal plate explant per clove (Haque et al., 1998).

A high frequency shoot regeneration from the root tip of garlic without intervening callus phase (Haque et al., 1997), proved that root is preferable and more efficient than any other explants. In spite of good success of root as explant, few reports (Fereol et al., 2005; Khan et al., 2004; Fereol et al., 2002; Robledo et al 2000) are available which utilized the root for somatic embryogenesis and yet no standard protocol is recommended. Hence, more studies are required to establish a suitable protocol for somatic embryogenesis from root explants. Therefore, in the present investigation root explants from two different sources (Bangladeshi and Japanese varieties) were used to observe their regeneration and somatic embryogenesis potentiality. The other objective of the study was to optimize the media components for the development of an efficient protocol for somatic embrygenesis. 


\section{Materials and Methods}

The study was conducted in the USDA-BIOTECH Laboratory of the Department of Biotechnology of Bangladesh Agricultural University from April, 2010 to December, 2011. Explants were taken from sprouted garlic cloves cultured on water agar. Garlic variety namely Japanese cv. white roppen and Bangladeshi garlic were taken to investigate there in vitro regeneration potentiality. Garlic cloves were surface sterilized with $70 \%$ alcohol for 30 sec and then $0.1 \% \mathrm{HgCl}_{2}$ solution with 2 drops Tween-20 per $100 \mathrm{ml}$ for 5 minutes subsequently washed by autoclaved distilled water for three times to remove trace of $\mathrm{HgCl}_{2}$ which would be toxic to the explant. The cloves were then ready for placement into the media.

Culture methods: Sterilized cloves were placed into sterilized sprouting medium in culture vessels and then incubated in dark till the sprouting of the cloves. After that it was transferred to $12 \mathrm{~h}$ light period. Within 3-5 days roots were initiated and ready for use as explants.

Explant culture: The aseptically grown seedlings were placed on a sterile vial. Young root tips measuring 2-3 $\mathrm{mm}$ in length were separated and placed in the sterile culture media containing different concentrations of 2,4-D. Two or three root tips were inoculated in each vial and covered with lid and sealed with parafilm.

Subculture or transfer: When the calli attained a convenient size they were removed aseptically from the culture vessels and placed on a sterile vial, inside the airflow cabinet. The calli were cut into small pieces and were placed into freshly prepared sterilized media with appropriate concentration of growth regulators. These were again sub-cultured to freshly prepared medium containing different hormone supplements for the maintenance of callus or for shoot-root differentiation. The culture vessels showing signs of contamination were discarded. Repeated sub-culturing was done at an interval of 15 days for the maintenance of calli.

Incubation: Culture vessels with inoculated explants were incubated both in dark and light condition under controlled temperature of $28^{\circ} \mathrm{C}$. About $16 \mathrm{~h}$ photoperiods with a light intensity of $2000-3000$ lux was maintained. Observation was carried out daily to note the response.

Preparation of pot: Potting mixture containing properly mixed ground soil and cowdung in the ratio of 1:1 and was placed into earthen pots for growing the plantlets in vivo condition after autoclaving.

Transfer of plantlets on to soil: When the plantlets became $3-5 \mathrm{~cm}$ in length with 2-3 well developed leaves and roots, then the plantlets were removed from the vials. Medium attached to roots was gently washed out with tap water. Plantlets were then transplanted to pots containing the above mentioned potting mixture.

Analysis of data: The data were analyzed using Complete Randomized Design (CRD) and the treatment mean is compared with the LSD (Least significant difference) test.

\section{Results}

\section{Initiation of callus and formation of somatic embryo}

Initiation of callus: The root explants were placed in the MS medium for callus induction. MS medium was supplemented with the various concentrations of 2,4-D. Callus development was varied significantly with the different concentrations of 2,4-D and there were also considerable varietal differences on callusing (Fig. 1). These effects are described below.

Main effect of 2,4-D and variety on callus induction: Maximum callus induction $(88.88 \%$ in local and $88.33 \%$ in exotic cultivars) and highest callus diameter $(0.65$ and $3.747 \mathrm{~cm}$ respectively for local and exotic variety) were achieved at $1.0 \mathrm{mg} \mathrm{I}^{-1} 2,4-\mathrm{D}$. Minimum callusing $(66.67 \%)$ were recorded at $2 \mathrm{mg} \mathrm{I}^{-1} 2$, 4-D and $1.5 \mathrm{mg} \mathrm{I}^{-1}$ 2, 4-D for Bangladeshi and Japanese cultivars respectively. These concentrations (2 $\mathrm{mg} \mathrm{l}^{-1} 2,4-\mathrm{D}$ and $\left.1.5 \mathrm{mg} \mathrm{l}^{-1} 2,4-\mathrm{D}\right)$ also gave the lowest callus diameter $(0.597 \mathrm{~cm}$ for local and $2.743 \mathrm{~cm}$ for Japanese variety). The results are presented in the Table 1. On the other hand, significant varietal differences were found between local and Japanese cultivars regarding the different callus inducing characters like \% callus initiation, callusing response, size of callus, and color and nature of callus (Table 3). Callusing response was better in local variety $(62.26 \%)$ than Japanese variety (43.33\%). But, Japanese cultivars showed highest callus diameter $(1.947 \mathrm{~cm})$. In addition to these, yellowish callus color was dominated in local variety and whitish color in exotic variety (Table 2 ). 
Table 1. Effect of different concentration of 2,4-D and different variety of garlic on $\%$ callus formation, days to callus initiation and diameter of callus $(\mathrm{cm})$

\begin{tabular}{|c|l|c|c|c|}
\hline $\begin{array}{c}\text { Concentration of 2,4-D } \\
\left(\mathrm{mg} \mathrm{L}^{-1}\right)\end{array}$ & Variety & \% callus formation & Days to callus initiation & $\begin{array}{c}\text { Diameter of callus } \\
(\mathrm{cm})\end{array}$ \\
\hline \multirow{3}{*}{0 (control } & Local & $0.000 \mathrm{~b}$ & $0.000 \mathrm{f}$ & $0.000 \mathrm{f}$ \\
\cline { 2 - 5 } & Exotic & $0.000 \mathrm{~b}$ & $0.000 \mathrm{f}$ & $0.000 \mathrm{f}$ \\
\hline \multirow{2}{*}{0.5} & Local & $72.440 \mathrm{a}$ & $14.000 \mathrm{e}$ & $0.617 \mathrm{e}$ \\
\cline { 2 - 5 } & Exotic & $66.670 \mathrm{a}$ & $22.000 \mathrm{~b}$ & $3.243 \mathrm{~b}$ \\
\hline \multirow{2}{*}{1.0} & Local & $88.887 \mathrm{a}$ & $17.000 \mathrm{~d}$ & $0.650 \mathrm{e}$ \\
\cline { 2 - 5 } & Exotic & $83.330 \mathrm{a}$ & $23.000 \mathrm{~b}$ & $3.747 \mathrm{a}$ \\
\hline \multirow{2}{*}{1.5} & Local & $83.330 \mathrm{a}$ & $18.000 \mathrm{~d}$ & $0.783 \mathrm{~d}$ \\
\cline { 2 - 5 } & Exotic & $66.670 \mathrm{a}$ & $25.333 \mathrm{a}$ & $0.743 \mathrm{c}$ \\
\hline \multirow{2}{*}{2.0} & Local & $66.670 \mathrm{a}$ & $20.000 \mathrm{c}$ & $0.597 \mathrm{e}$ \\
\cline { 2 - 5 } & Exotic & $0.000 \mathrm{~b}$ & $0.000 \mathrm{f}$ & 1.28 \\
\hline \multicolumn{2}{|c|}{$\mathrm{CV} \mathrm{( \% )}$} & 29.30 & 6.02 & 0.07116 \\
\hline \multicolumn{2}{|c|}{$\operatorname{LSD}_{(0.05)}$} & 35.07 & 1.897 & \\
\hline
\end{tabular}

Table 2. Effect of local and exotic variety of garlic on \% callus formation, days to callus initiation and size of callus $(\mathrm{cm})$

\begin{tabular}{|l|c|c|c|c|c|}
\hline \multicolumn{1}{|c|}{ Variety } & $\begin{array}{c}\text { Per cent callus } \\
\text { formation }\end{array}$ & $\begin{array}{c}\text { Days to callus } \\
\text { initiation }\end{array}$ & $\begin{array}{c}\text { Diameter of } \\
\text { callus }(\mathrm{cm})\end{array}$ & Color of callus & $\begin{array}{c}\text { Nature of } \\
\text { callus }\end{array}$ \\
\hline Local & $62.265 \mathrm{a}$ & $13.8 \mathrm{a}$ & $0.529 \mathrm{~b}$ & Yellowish & Compact \\
\hline Exotic & $43.332 \mathrm{a}$ & $14.0 \mathrm{a}$ & $1.947 \mathrm{a}$ & Whitish & Compact \\
\hline $\mathrm{CV}(\%)$ & 29.30 & 6.02 & 1.28 & & \\
\hline $\mathrm{LSD}_{(0.05)}$ & 71.77 & 3.882 & 0.1467 & & \\
\hline
\end{tabular}

Combined effect of 2,4-D and variety on callus induction: During observing the combined effect, it was found that frequency of callus induction and callus diameter was the highest $(86.10 \%$ and $2.19 \mathrm{~cm}$ respectively) at $1.0 \mathrm{mg} \mathrm{I}^{-1} 2,4-\mathrm{D}$ and lowest $\left(33.33 \%\right.$ and $0.29 \mathrm{~cm}$ respectively) at $2.0 \mathrm{mg} \mathrm{I}^{-1} 2,4-\mathrm{D}$. The frequency of callus formation was lower at higher concentration of 2,4-D. There was no callus formation on 2,4-D free medium (Table 3).

Table 3. Combined effect of 2,4-D on \% callus formation, days to callus initiation, and diameter of callus $(\mathrm{cm})$ of local and exotic variety of garlic

\begin{tabular}{|l|c|c|c|}
\hline $2,4-\mathrm{D}\left(\mathrm{mg}^{-1}\right)$ & \% callus formation & Days to callus initiation & Diameter of callus (cm) \\
\hline 0 (control) & $0 \mathrm{c}$ & $0.000 \mathrm{e}$ & $0.000 \mathrm{e}$ \\
\hline 0.5 & $69.550 \mathrm{a}$ & $18.000 \mathrm{c}$ & $1.930 \mathrm{~b}$ \\
\hline 1.0 & $86.108 \mathrm{a}$ & $20.000 \mathrm{~b}$ & $2.198 \mathrm{a}$ \\
\hline 1.5 & $75.002 \mathrm{a}$ & $21.5 \mathrm{a}$ & $1.763 \mathrm{c}$ \\
\hline 2.0 & $33.333 \mathrm{~b}$ & $10.000 \mathrm{~d}$ & $0.298 \mathrm{~d}$ \\
\hline $\mathrm{CV}(\%)$ & 29.30 & 6.02 & 1.28 \\
\hline $\mathrm{LSD}_{(0.05)}$ & 24.80 & 1.341 & 0.05069 \\
\hline
\end{tabular}

Formation of somatic embryo: The developing callus was sub-cultured on the same medium for inducing the somatic embryo. The callus morphology was changed on continuous sub-culturing for the further 7 weeks in the same medium as described above. The calli proliferated and turned nodular. Subsequently, globular embryo-like structure (Fig. 2) developed extensively on the surface of almost all the proliferated calli in the presence of $0.5-1.5 \mathrm{mg} \mathrm{l}^{-1} 2,4-\mathrm{D}$.

Plantlet regeneration from somatic embryo: For the induction of shoots as well as roots from embryogenic calli, one callus/vial from exotic variety of garlic was set. Plantlet development (Fig 3A) was evident on MS medium supplemented with different concentrations of kinetin. Formation of shoots and roots in developing plantlet was initiated by the germination of somatic embryos (Fig. 4) in the culture medium. However, the frequency of shoot regeneration varied greatly with the different concentrations of kinetin. In the present study, the highest frequency of regeneration was found on $2.0 \mathrm{mg} \mathrm{I}^{-1}$ kinetin (Fig. 3B). Induction of multiple plantlets was also better in the medium with $2.0 \mathrm{mg} \mathrm{l}^{-1}$ Kinetin. The morphogenic responses of callus to various concentrations of kinetin have been shown in the Table 4 and effect of kinetin and variety on plantlet regeneration is discussed here. 
Main and combined effect of kinetin and variety on plantlet regeneration from somatic embryo: MS medium supplemented with different concentrations of kinetin $\left(0.0,1.0\right.$ and $\left.2.0 \mathrm{mg} \mathrm{I}^{-1}\right)$ showed wide variations in shoot formation. The highest number of shoots (4.670) per callus was found in MS $+2.0 \mathrm{mg}$ $\mathrm{I}^{-1}$ kinetin. The longest length of shoots $\left(7.0 \mathrm{~cm}\right.$ ) per callus was found in $\mathrm{MS}+2.0 \mathrm{mg} \mathrm{I}^{-1}$ kinetin (Table 4). For shoot formation, maximum number of days required was 10.677 and minimum was 9.0 days. The number of plantlets \& days required for plantlet formation was found statistically different. Number of plantlets/callus in exotic variety was 4.21 and days required for shoot formation was 9.83 .

Table 4. Effect of exotic variety of garlic on number of callus incubated, no. of callus showing shoot and \% shoot induction

\begin{tabular}{|l|c|c|c|c|c|c|}
\hline $\begin{array}{l}\text { Kinetin } \\
\left(\mathrm{mg} \mathrm{l}^{-1}\right)\end{array}$ & $\begin{array}{c}\text { Number of } \\
\text { callus } \\
\text { incubated }\end{array}$ & $\begin{array}{c}\text { Number of } \\
\text { callus showing } \\
\text { shoot }\end{array}$ & $\begin{array}{c}\text { \% shoot } \\
\text { induction }\end{array}$ & $\begin{array}{c}\text { Days to } \\
\text { shoot } \\
\text { induction }\end{array}$ & $\begin{array}{c}\text { No. of } \\
\text { shoot/ } \\
\text { callus }\end{array}$ & $\begin{array}{c}\text { Length } \\
\text { of shoot } \\
\text { (cm) }\end{array}$ \\
\hline 0 (control) & $0.000 \mathrm{c}$ & $0.000 \mathrm{c}$ & $0.000 \mathrm{c}$ & 0.000 & $0.000 \mathrm{c}$ & $0.000 \mathrm{c}$ \\
\hline 1.0 & $10.000 \mathrm{~b}$ & $7.667 \mathrm{~b}$ & $70.000 \mathrm{~b}$ & 10.667 & $3.750 \mathrm{~b}$ & $5.333 \mathrm{~b}$ \\
\hline 2.0 & $15.000 \mathrm{a}$ & $12.000 \mathrm{a}$ & $80.000 \mathrm{a}$ & 9.000 & $4.670 \mathrm{a}$ & $7.000 \mathrm{a}$ \\
\hline $\mathrm{CV}(\%)$ & 9.80 & 18.33 & 7.39 & 13.45 & 0.58 & 16.22 \\
\hline $\mathrm{LSD}_{(0.05)}$ & 1.632 & 2.401 & 7.386 & 1.762 & & 1.331 \\
\hline
\end{tabular}

Hormone free MS medium for further development of the shoot and root: MS medium without hormone was used in exotic variety of garlic (Japanese) in order to achieve further development of the regenerated plantlets (Fig. 5) from somatic embryo. Plantlet regeneration was not found from all the somatic embryos. Some of them disappeared while others formed roots only on the regeneration medium.

\section{Discussion}

The ultimate goal of this experiment was plant regeneration via embryogenic calli. To achieve this goal root tips of two garlic varieties were cultured on MS medium supplemented with different concentrations of 2,4-D to observe their callus and somatic embryo inducing potentiality.

Within the three weeks of culture, callus formation began only at the meristematic region of the root tips. Root tips increased in size on the medium containing $0.5 \mathrm{mg} \mathrm{l}^{-1} 2,4-\mathrm{D}$ while those on the medium containing $2.0 \mathrm{mg} \mathrm{l}^{-1} 2,4-\mathrm{D}$ became pink and necrotic. The frequency of callus formation, as recorded after 6 weeks of culture initiation, varied notably with the 2,4-D concentration (Table 1). The percentage of callus formation was lower at higher concentration of 2,4-D. In case of both local and Japanese cultivars, callus size gradually increased when the media contained $0.5-1.5 \mathrm{mg} \mathrm{I}^{-1} 2,4-\mathrm{D}$. There was no callus formation on 2,4-D-free medium. The findings demonstrate that callus induction from root explants is strongly reliant on the 2,4-D concentration in the medium. Novak (1990) and Luciani el al,. (2006) also found that callus induction and growth in Allium is strictly enhanced by the presence of exogenous auxins in the growth medium.

The present study observed that a low range $\left(0.5-1.5 \mathrm{mg} \mathrm{I}^{-1}\right)$ of 2,4-D was the effective concentration in the case of garlic root explants. This concentration of 2,4-D seems to be very low and cope well with the findings of other reports (Khan et al., 2004; Fereol et. al., 2002; Robledo et al., 2000; Barandiaran et al., 1999). Our result recommend that $1.0 \mathrm{mgl}^{-1} 2,4-\mathrm{D}$ is the optimum concentration for plantlet regeneration form root tip explants which is slightly higher than that suggested by Haque et al,. (1998) but we achieved the more frequency of callus induction. In addition, it was found that higher 2,4-D levels had a suppressive effect on callus induction and plantlet regeneration. High concentration of 2,4-D decreased the percentage of regenerative calli as well as the number of regenerated plantlets per explant by decreasing in the formation and development of embryos. Lee et al,. (2009) also suggested that high 2,4$\mathrm{D}$ is inhibitory for somatic embryo development in the advanced stages. Thus, it appears that 2,4-D might play an important role in plant regeneration particularly from Allium root-callus and using optimum concentration is efficient for achieving better result. 
It was also observed that callusing ability of the local cultivars was slower than the Japanese cultivars and no regeneration was achieved during the study period. Hence, Japanese cultivar was used for the development of somatic embryo and subsequent plantlet regeneration. The embryos started to germinate (Fig 3A) 1-2 weeks after transfer to MS medium supplemented with different concentrations of kinetin $\left(0.0,1.0,2.0, \mathrm{mg} \mathrm{l}^{-1}\right)$. The germination was characterized by gradual greening and enlargement of the cotyledon (Fig 3). The germinating embryo could be separated into a single that exhibited a bipolar development of root and shoot (Fig 4). The presences of radicles in the germinating embryos enabled us to identify the somatic embryos. The results revealed that no shoots regenerated from callus when kinetin was omitted from the medium (Table 4). It indicates that kinetin must be added to the medium for plantlet formation from embryogenic calli of garlic. Kinetin also showed promoting role in somatic embryogenesis in several other reports (Zdravkovic-Koracet al., 2010; Lee et al., 2009; Khan et al., 2004; Haque et al., 1998).

Hormone free MS medium was used for further development (Fig. 5) of regenerated plantlet from somatic embryo. In this case some of the embryos were disappeared and did not form root the cause of which is not clear to us and further investigation is required to identify the causes. Rooting of in vitro shoots is important for successful regeneration of plantlets. Garlic has been reported to develop roots easily in vitro culture. Various reports are available on the rooting of garlic shoots. Haque et al. (1997) and Khan et al., (2004) reported that garlic shoots develop roots on hormone free MS medium and the same hormone free media help in proper development of shoots and roots of the somatic embryo derived plantlets (Haque et al., 1998). Zdravkovic-Korac et al,. (2010) also found the similar results.
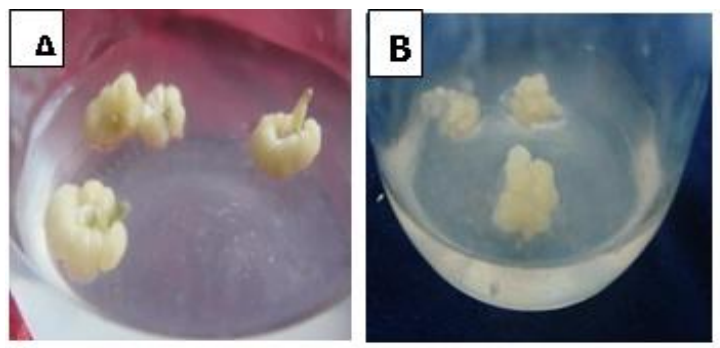

Fig. 1. Initiation of callus of local variety $(A)$ and Japanese variety $(B)$ at $1.0 \mathrm{mg} \mathrm{l}^{-1}$
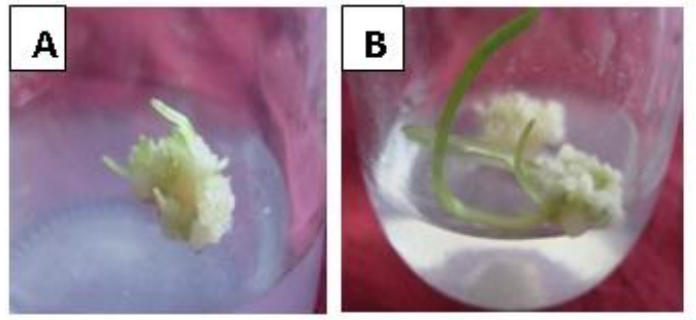

Fig. 3. Development and formation of plantlet from the somatic embryo in the medium with MS+2.0 $\mathrm{mg} \mathrm{l}^{-1}$ kinetin
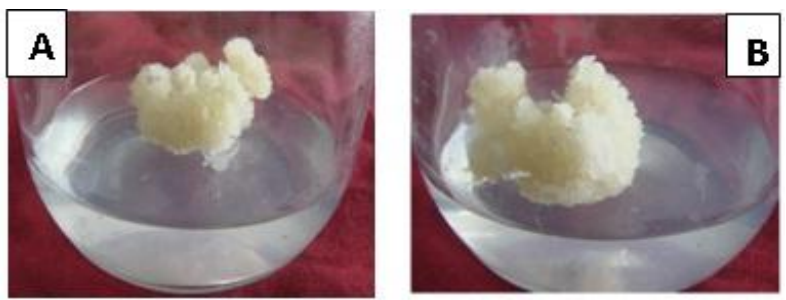

Fig. 2. Callus and somatic embryo induction from root tips of Japanese variety A medium with $0.5 \mathrm{mg} \mathrm{I}^{-1}$ 2, 4-D \& B medium with $1.0 \mathrm{mg} \mathrm{I}^{-1} 2,4-\mathrm{D}$
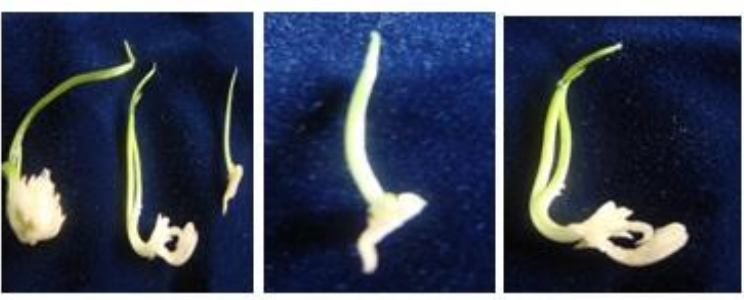

Fig. 4. Germination of somatic embryo showing roots and shoots
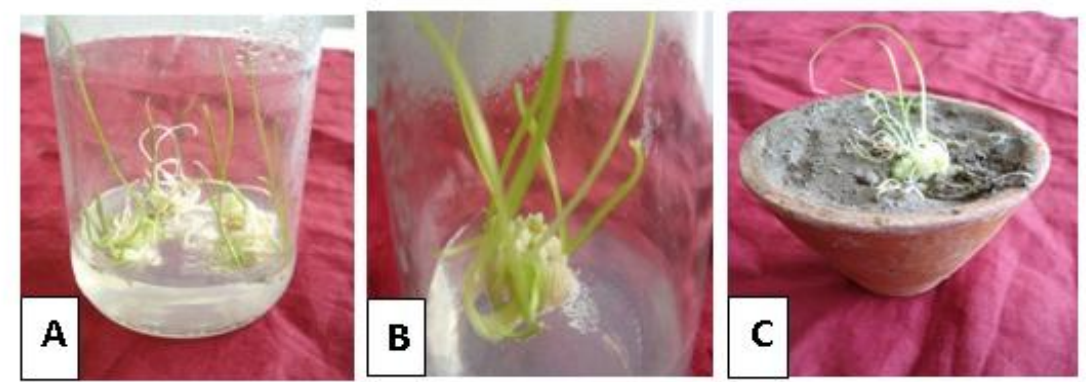

Fig. 5. (A) Further development of somatic embryo derived plantlets, (B) Plantlets on growth regulator-free medium, (C) Plantlets established in pot 


\section{Conclusion}

The study demonstrated good success of root tip as explants for in vitro plant regeneration of garlic through somatic embryogenesis. The investigation also found some growth regulator combination which gave excellent performances regarding callus induction and somatic embryo production. The protocol described here used a single hormonal signal to induce callus and somatic embryo and hormone free medium for plant regeneration from somatic embryo. Thus the protocol is cost effective. Besides, a high success rate was achieved comparatively within short period of time. Therefore, the protocol can be widely used for rapid in vitro plant regeneration of garlic in commercially feasible way. Moreover, genetic improvement of garlic requires an efficient tissue culture protocol and the protocol stated here can be a good supplement in this respect.

\section{References}

Barandiaran, X., Martin, N., Rodriguez-Conde, M.F, Di Pietro, A. and Martin, J. 1999a. An efficient method for callus culture and shoot regeneration of garlic (Allium sativum L.). Hort Sci 34(2): 348-349.

Fereol, L., Chovelon, V., Causse, S., Michaux-Ferriere, N. and Kahane, R. 2002. Evidence of a somatic embryogenesis process for plant regeneration in garlic (Allium sativum L.). Plant Cell Rep 21: 197-203.

Fereol, L., Chovelon, V., Causse, S., Triarie, D., Arnault, I., Auger, J. and Kahane, R. 2005. Establishment of embryogenic cell suspension cultures of garlic (Allium sativum L.), plant regeneration and biochemical analyses. Plant Cell Rep. 24:319325.

Haque, M.S., Wada, T. and Hattori, K. 1997. High frequency shoot regeneration and plantlet formation from root tip of garlic. Plant Cell Tiss Org Cult 50: 83-89.

Haque, M.S., Wada, T. and Hattori, K. 1998. Efficient plant regeneration in garlic through somatic embryogenesis from root tip explants. Plant Prod Sci 3: 216-222.

Haque, M.S., Wada, T. and Hattori, K. 2003. Shoot Regeneration and Bulblet Formation from Shoot and Root Meristem of Garlic Cv Bangladesh Local. Asian J Plant Sci 2 (1): 23-27.

Khan, N., Alam, M.S. and Nath, U.K. 2004. In vitro Regeneration of Garlic Through Callus Culture. J Biol Sci 4 (2): $189-191$.

Lee, S.K., Kim, H.H., Kim, Y.K., Park, N. and Park, S.U. 2009. Plant regeneration of garlic (Allium sativum L.) via Somatic embryogenesis. Sci Res Essay 4 (13): 1569-1574.

Luciani, G.F., Mary, A.K., Pellegrini, G. and Curvetto, N.R. 2006. Effects of explants and growth regulators in garlic callus formation and plant regeneration. Plant Cell Tiss Organ Cult 87: 139-143.

Nasim, S.A., Mujib, A., Kapoor, R., Fatima, S. and Aslam J. Mahmooduzzafar, 2010. Somatic embryogenesis in Allium sativum L. (cv. Yamuna Safed 3): Improving embryo maturation and germination with PGRs and carbohydrates. Anales de Biología 32: 1-9.

Novak, F.J. 1990. Allium tissue culture. In: Rabinowitch HD, Brewster JL, Brewster eds. Onions and Alied Crops. Vol. I, Botany Physio. Genet. CRC Press, Boca Raton 234-250.

Robledo-Paz, A., Vilalobos-Arambula, V.M. and Jofre-Garfias, A.E. 2000. Efficient plant regeneration of garlic (Allium sativum L.) by root tip culture. In Vireo Cell Dev Plant 36: 416-419.

Roksana, R., Alam, M.F., Islam, R. and Hossain, M.M. 2002. In vitro Bulblet Formation from Shoot Apex in Garlic (Allium sativum L.). Plant Tiss Cult 12(1): 11-17.

Zdravkovic-Korac, S., Milojevic, J., Tubic, L., alic-Dragosavac, D.C., Mitic, N. and Vinterhalter, B. 2010. Somatic embryogenesis and plant regeneration from root sections of Allium schoenoprasum L. Plant Cell Tiss Organ Cult 101: 237-244. 